Journal of Engineering and Applied Sciences 14 (Special Issue 8): 10311-10317, 2019

ISSN: 1816-949X

(C) Medwell Journals, 2019

\title{
In the Way of having an Optimum Wireless Ad-Hoc Sensor Networks: Analysis of Deploying Homogeneous and Inhomogeneous Nodes
}

\author{
${ }^{1}$ Abbas B. Noori, ${ }^{1}$ Maral A. Mustafa, ${ }^{2}$ Farooq Safauldeen Omar, \\ ${ }^{3}$ Firat Kacar and ${ }^{1}$ S.F. Mohammed \\ ${ }^{1}$ Kirkuk Technical Institute, \\ ${ }^{2}$ Kirkuk Technical Collage, Northern Technical University, Kirkuk, Iraq \\ ${ }^{3}$ Engineering Collage, Istanbul University, Istanbul, Turkey
}

\begin{abstract}
The emerging technology of ad-hoc sensor networks helped to increase researches in this field due to a large number of applications that uses wireless ad hoc networks such as monitoring of the environment, intelligent agriculture, structure health, earthquake prediction, industrial control and target detection in military applications. Various analyses have been suggested for optimality of ad hoc networks; in our study for a given number of nodes we use a comparative analysis by using two kinds of sensors network, the first network with different type of sensors having different connectivity range and sensing coverage and the other network with same capabilities for sensors in terms of connectivity and coverage range and the aim is to have a clear view about the utility of deploying homogeneousor inhomogeneous wireless ad hoc sensor network. Analysis of sensors deployment with a homogeneous transmission range reveals better network connectivity. Therefore, deploying sensor nodes with different transmission range does not improve the connectivity of the network when a power constraint present. In addition, using inhomogeneous nodes does not help to reduce power consumption to maintain network availability.
\end{abstract}

Key words: Wireless ad-hoc networks, network connectivity, power consumption, phase transition, inhomogeneous, target detection

\section{INTRODUCTION}

The Wireless Sensor Networks (WSN) coverage and connectivity are necessary because good coverage means receiving reliable information from the monitored place by the network deployed in the monitored field, therefore, connectivity between nodes play an essential role in network connectivity. Ad-hoc (WSN) try to communicate with each other using multi-hop manner in order to deliver a packet of data sent from source to the base unit or the sink, the effect of environmental parameters and constraints of power consumption in these small sensors lead to counter many difficulties in terms of coverage or connectivity (Akyildiz and Vuran, 2010). These large numbers of randomly separated tiny nodes are power constrained and deployed to monitor multiple sensed things; hence, they need to remain active for a long time. Signal processing, idle listening and transmitting-receiving of the signal are the main reasons for power consumption. Therefore, the main challenge in the design of sensor networks is energy conservation. Furthermore, since, nodes are planned to be deployed in the area for a long time, serious problems can be encountered in the network if a node does not work properly. In this study, analysis is carried out for the connection in the ad hoc network whose nodes are connected wirelessly and then graph theory concepts are considered to analyze whether wireless sensor nodes can be used to communicate wirelessly with each other where as connectivity doesn't certainly mean coverage or vice versa. Power saving might occur if the sensing range is reduced or statements of some sensor nodes are changed from active to idle which needs manipulating some complex protocols.

Literature review: Recent years have witnessed many types of research in ad-hoc wireless sensor networks connectivity and coverage related issues, a brief revision for existing works will be present as follows; coverage and connectivity studies have shown by Xing et al. (2005) Ammari and Das (2008) and Khanjary et al. (2014) proved that when transmitting range is at least twice sensing range then the nodes are connected if the coverage is guaranteed.

The researcher by Philips et al. (1989) approved that the possibility of adjacent nodes number must increase logarithmically with network region to have a connected network; the presence of a critical value was also seen for

Corresponding Author: Abbas B. Noori, Kirkuk Technical Institute, Northern Technical University, Kirkuk, Iraq 
the required amount of the nearest neighbors of the node with an infinite linked component in an infinite region. Miorandi and Altman (2005) developed a way of calculating the probability of isolation for network nodes during the existence of channel randomness for distributed nodes. By Liu the researchers presented: full, partial and limited connectivity coverage. It has been shown that two simple network topologies meet the limited coverage of the connectivity criterion. The minimum density of nodes required for the establishment of a connected wireless network for Rayleigh fading channels was shown according to the results obtained, the wireless sensor network connectivity degraded due to the fading effect. Researcher by Dung and An (2015) and Dousse et al. (2002) studied randomly distributed multi-hop wireless networks connectivity but the closest work to the one described in this research is Dousse et al. (2002) he investigated nodes with two assignments homogeneous and in homogeneous range.

The researcher by Kong and Yeh (2007) Dousse et al. (2002) and Lu et al. (2012) studied the percolation model and the continuum percolation model particularly for the analysis of large-scale wireless ad-hoc networks they showed if the nodes are spread at low density then the network will be divided into small fragments, if it has an extremely big connected component then the network can be considered to be percolated. The critical phase transition for large scale wireless ad hoc networks was investigated by Xing and Wang (2008) when the network topology experiences fragmenting due to increased random node failures, the phenomenon of phase transition can be defined as a sudden and extreme change from a subcritical to a supercritical phase.

\section{MATERIALS AND METHODS}

The graph theory by Diestel (2016) describes a graph as a pair of sets where the components are the points of the graph and a component requires a neighbor in order to stay connected and also a graph is referred to as a directed graph if the edges connecting the points are one-way; else, the graph can be considered undirected graph.

Large scale nodes which are randomly distributed is considered in this study and (Poisson point process) assumption is used to describe the location of the sensor nodes, stationary homogeneous spatial Poisson point process is satisfied by the following conditions as mentioned by Chiu et al. (2013) and Chen et al. (2018). Points that occur in side a limited Area (Ax) is a random variable with mean $\varphi|\mathrm{Ax}|$ that uses a Poisson distribution for constant $\varphi$ where $|\mathrm{Ax}|$ is the area of $\mathrm{Ax}$.

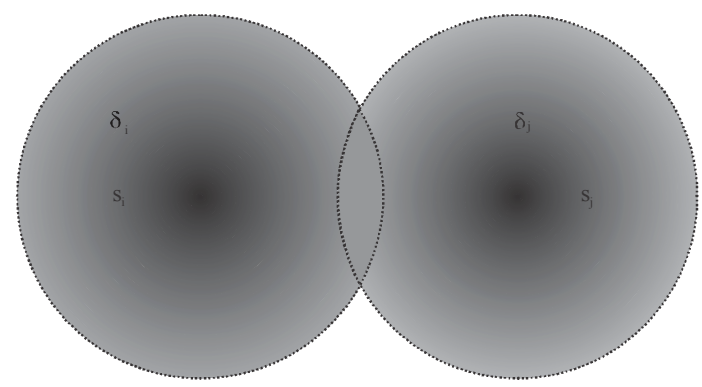

Fig. 1: A graphical design of wireless sensors nodes communication

Total number presumed in the points $(\mathrm{m})$ that taking place in $(\mathrm{Ax})$, locations of the $(\mathrm{m})$ points describe a (self-determining) random sample of $(\mathrm{m})$ positions where every position has an equal probability to be selected in the region.

Therefore, the constraint of the Poisson process to the region $(\mathrm{Ax})$ with a condition that $\mathrm{Ax}$ has $\mathrm{m}$ points returns a binomial process for $\mathrm{m}$ point which is outlined assuming that the arbitrary point (a) is distributed uniformly in the area $(\mathrm{Ax})$ if:

$$
\mathrm{P}_{\mathrm{n}}(\mathrm{a} \in \mathrm{b})=\frac{|\mathrm{b}|}{|\mathrm{Ax}|}
$$

For all regions (b) in Ax. The power of the binomial process for the points is characterized by and given by:

$$
\varphi=\frac{\mathrm{m}}{|\mathrm{Ax}|}
$$

Simulation model and assumptions: The study scenario will presume that $\mathrm{X}$ nodes are installed in an $\mathrm{x}$ area. The node density will then be equal to:

$$
\varphi=\frac{X}{\left(L_{s}\right)^{2}}(3)
$$

Some modeling assumptions are outlined in Fig. 1. Let $Z_{\varphi}=\left\{\delta_{i}: \quad i \geq 1\right\}$ represent "two dimensional homogeneous Poisson point process" Khanjary et al. (2014) with density $\varphi$ where $\delta_{i}$ represents the location of the sensor $s_{i}$. Let $Z_{\varphi}\left(L_{s}\right)$ be an a random variable that represent the number of the points in a defined area $\mathrm{b}=\mathrm{L}_{\mathrm{s}} \times \mathrm{L}_{\mathrm{s}}$ then the probability of having $\mathrm{X}$ points inside $\mathrm{b}$ is computed as:

$$
\left.\mathrm{p}\left(\mathrm{Z}_{\varphi}\left(\mathrm{L}_{\mathrm{s}}\right)\right)=\mathrm{X}\right)=\frac{\varphi^{\mathrm{X}}|\mathrm{b}|^{\mathrm{X}} \mathrm{e}^{-\varphi|\mathrm{b}|}}{\mathrm{X} !}
$$


For all $X \geq 0$ where $|b|$ is the size of $b$ s area. The setup of the network in the simulation scenario is arranged by using two kinds of sensor nodes; the first model has a Small Communication Range (SCR) and the sec model has a Large Communication Range (LCR). It is worthy to mention here that the use of such kinds of nodes that have large transmission capability will lead to consuming more power.

Since, the study uses two kinds of nodes in sensor deployment, therefore, two plans for placement of nodes are tested; (homogeneous) and (Inhomogeneous) sensor nodes (in terms of communication range). For simulation determinations, the exponent of path $\operatorname{loss} \lambda$ is set to 3 . Nodes randomly deployed using $80,160,320$ and 640 sensor nodes and the effects of placing these types of nodes on the connectivity of the deployment region were investigated (Table 1).

Table 1: The parameters used to obtain simulation results

\begin{tabular}{lll}
\hline Parameters & Notations & Values \\
\hline $\begin{array}{l}\text { Large communication } \\
\text { range node }\end{array}$ & $\mathrm{Lc}_{\mathrm{r}}$ & $\begin{array}{l}\text { (try 1) } \mathrm{Lc}_{\mathrm{r}}=3-50 \mathrm{~m} \\
\text { (try 2) } \mathrm{Lc}_{\mathrm{r}}=7-50 \mathrm{~m}\end{array}$ \\
$\begin{array}{l}\text { Small communication } \\
\text { range node }\end{array}$ & $\mathrm{Sc}_{\mathrm{r}}$ & $\begin{array}{l}\text { (try 1) } \mathrm{Sc}_{\mathrm{r}}=3 \mathrm{~m} \\
\text { (try 2) } \mathrm{Sc}_{\mathrm{r}}=7 \mathrm{~m}\end{array}$ \\
$\begin{array}{l}\text { LCR nodes ratio } \\
\text { Nodes deployment number }\end{array}$ & $\mathrm{L}_{\mathrm{r}}$ & $\{0.06,0.12,0.24,0.48\}$ \\
$\begin{array}{l}\text { The assumed exponent of } \\
\text { path loss }\end{array}$ & $\lambda$ & $\{80,160,240,320,400\}$ \\
$\begin{array}{l}\text { The assumed area size } \\
\text { Homogeneous nodes range }\end{array}$ & $\mathrm{S}_{\mathrm{r}}$ & 3 \\
\hline
\end{tabular}

\section{RESULTS AND DISCUSSION}

Figure 2 displays the results for network simulations of wireless sensors with pure homogeneous nodes. It is clearly can be seen that the connectivity is higher when more nodes are used. Sensor nodes connectivity range has also its influence. It reaches almost $100 \%$ when $\mathrm{N}_{\mathrm{d}}=400$. The network connectivity increases sharply after a certain point, this phenomenon is called (phase transition) which is a sudden change of small disconnected clusters to turn into a single large connected component (Xing and Wang, 2008).

On the other hand, the scenario of using inhomogeneous nodes has shown interesting results, nodes with different transmission ranges LCR and SCR have been used in the simulation with the given environment. Requirements of power consumption will be considered to evaluate the plan the energy consumption of homogeneous sensor nodes deployment is equivalent to $\mathrm{Sr}^{\lambda}$ ) (Table 2). The energy consumed by inhomogeneous nodes and homogenous distribution $\left(1-\mathrm{L}_{\mathrm{r}}\right) \mathrm{Scr}^{\lambda}+\mathrm{L}_{\mathrm{r}}\left(\mathrm{Lc}_{\mathrm{r}}\right)^{\lambda}$. The energy ratio in the (Homogeneous) case to that in (Inhomogeneous) case is determined by:

$$
\text { Energy consumption ratio }=\frac{\left(1-\mathrm{L}_{\mathrm{r}}\right) \mathrm{Scr}^{\lambda}+\mathrm{L}_{\mathrm{r}}\left(\mathrm{Lc}_{\mathrm{r}}\right)^{\lambda}}{\left(\mathrm{S}_{\mathrm{r}}\right)^{\lambda}}
$$

Figure 3 the energy ratio with a communication range $\mathrm{Sc}_{\mathrm{r}}=3 \mathrm{~m}$ for (SCR) sensor nodes and from $\mathrm{Lc}_{\mathrm{r}}=3 \mathrm{~m}$ to

Table 2: The ratio $\mathrm{Lc}_{\mathrm{r}} / \mathrm{Sc}_{\mathrm{r}}$ for energy ratio equal to 2

\begin{tabular}{|c|c|c|c|c|}
\hline Ratio of L $\gamma /$ Ranges (m) & $\mathrm{L}_{\mathrm{r}}=0.06$ & $\mathrm{~L}_{\mathrm{r}}=0.12$ & $\mathrm{~L}_{\mathrm{r}}=0.24$ & $\mathrm{~L}_{\mathrm{r}}=0.48$ \\
\hline $\begin{array}{l}\mathrm{Sc}_{\mathrm{r}}=3 \\
\mathrm{Lc}_{\mathrm{r}}=3-50\end{array}$ & $\mathrm{Lc}_{\mathrm{r}} / \mathrm{Sc}_{\mathrm{r}}=17.5$ & $\mathrm{Lc}_{\mathrm{r}} / \mathrm{Sc}_{\mathrm{r}}=13.9$ & $\mathrm{Lc}_{\mathrm{r}} / \mathrm{Sc}_{\mathrm{r}}=11.1$ & $\mathrm{Lc}_{\mathrm{r}} / \mathrm{Sc}_{\mathrm{r}}=7.4$ \\
\hline $\begin{array}{l}\mathrm{Sc}_{\mathrm{r}}=7 \\
\mathrm{Lc}_{\mathrm{r}}=7-50\end{array}$ & $\mathrm{Lc}_{\mathrm{r}} / \mathrm{Sc}_{\mathrm{r}}=5.7$ & $\mathrm{Lc}_{\mathrm{r}} / \mathrm{Sc}_{\mathrm{r}}=4.4$ & $\mathrm{Lc}_{\mathrm{r}} / \mathrm{Sc}_{\mathrm{r}}=3.6$ & $\mathrm{Lc}_{\mathrm{r}} / \mathrm{Sc}_{\mathrm{r}}=2.5$ \\
\hline
\end{tabular}

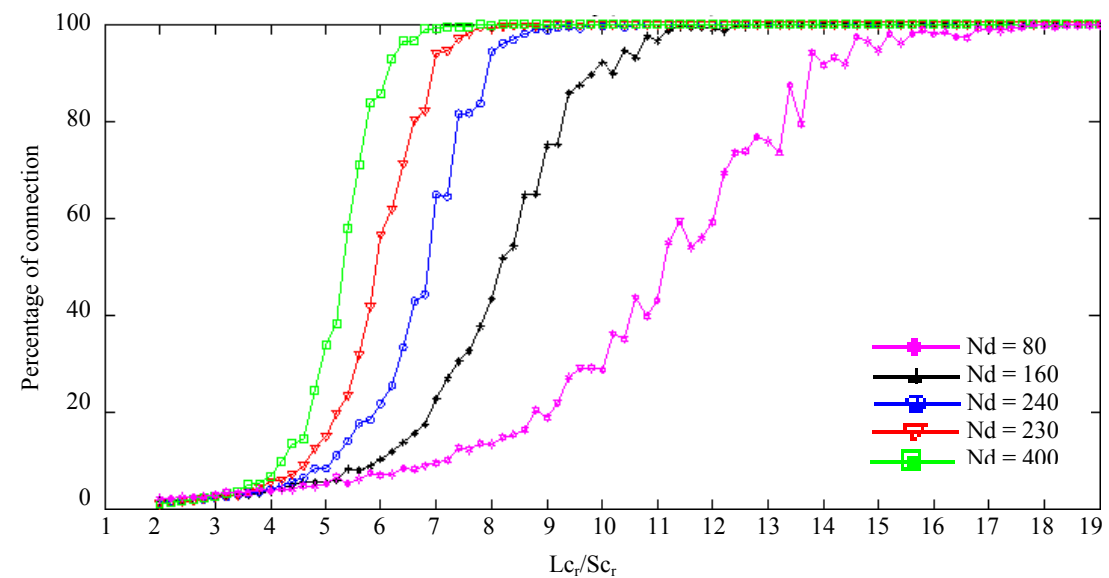

Fig. 2: Measurements of connectivity by using homogeneousness or node sat $N_{d}=(80,160,240,320$ and 400$)$ in the network (calculation of average more than 30 runs) 
$\mathrm{Lc}_{\mathrm{r}}=50 \mathrm{~m}$ for (LCR) sensor nodes and the homogeneous communication range $=8 \mathrm{~m}$ with a path loss exponent configured to be Eq. 3. The energy ratio rises rapidly as can be seen in Fig. 4 when the ranges of $\mathrm{Sc}_{\mathrm{r}}$ enlarged from 3-7 $\mathrm{m}$ and $\mathrm{Lc}_{\mathrm{r}}$ from 3-7 $\mathrm{m}$ as well comparing to the ratio of the LCR nodes.

By defining the energy consumption ratio equivalent to Eq. 2, the installation strategy of using two types of sensor nodes could be compared as Table 2 summarizes $\mathrm{Lc}_{\mathrm{r}} / \mathrm{Sc}_{\mathrm{r}}$ identified with Fig. 3 and 4 in inhomogeneous cases.

A critical range is a range needed to connect the sensor node network. If any sensor's range is smaller than

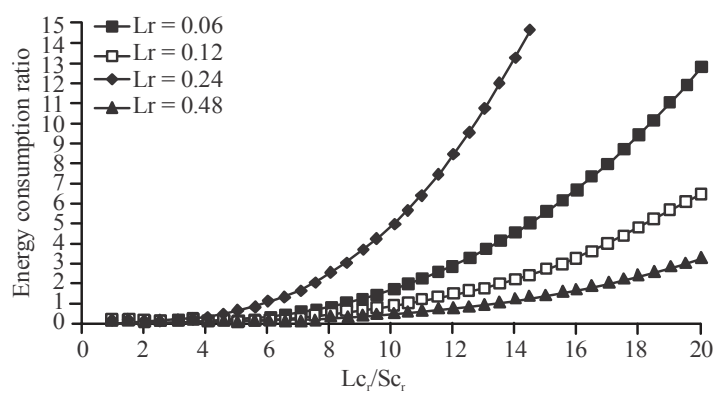

Fig. 3: Ratio of consumed energy by sensor nodes at $\lambda=3, \mathrm{Sc}_{\mathrm{r}}=8 \mathrm{~m}, \mathrm{~S}_{\mathrm{r}}=3 \mathrm{~m}, \mathrm{Lc}_{\mathrm{r}}=3-50 \mathrm{~m}$ the critical range, even if the other range is very high, a connected network cannot be achieved. Similar findings for undirected graph networks were founded by Bettstetter (2002).

The level of connectivity improves when we make the LCR nodes approach $48 \%$ of the total nodes deployed but have not yet reached $100 \%$ of connectivity as shown in Fig. 5 and 6. Although, 400 sensor nodes are distributed, the desired connectivity is still below the target level. Figure 5 shows that connectivity barely exceeds $70 \%$ when the LCR node ratio is 0.48 and is lower for ratios $(0.06,0.12$ and 0.24 ) with node numbers 80,160 and 320 . Table 3 shows the summarized results when and compared to homogeneous deployment results Fig. 5 and 6 are just two samples from the obtained results which are summarized in Table 3.

After using nodes with a range $\mathrm{Sc}_{\mathrm{r}}=3 \mathrm{~m}$ as shown in Fig. 5 and 6 the behavior is approximately similar when the range increases to $\mathrm{Sc}_{\mathrm{r}}=7 \mathrm{~m}$ as presented in Fig. 7 and 8 which are samples for the found results. Table 4 reviews the results of using in homogeneous strategy for deployment when the ranges are $\mathrm{Sc}_{\mathrm{r}}=8 \mathrm{~m}$ and $\mathrm{Lc}_{\mathrm{r}}=7-50 \mathrm{~m}$.

From all the results and caparisons that carried out, it is clear that the homogeneous deployment strategy

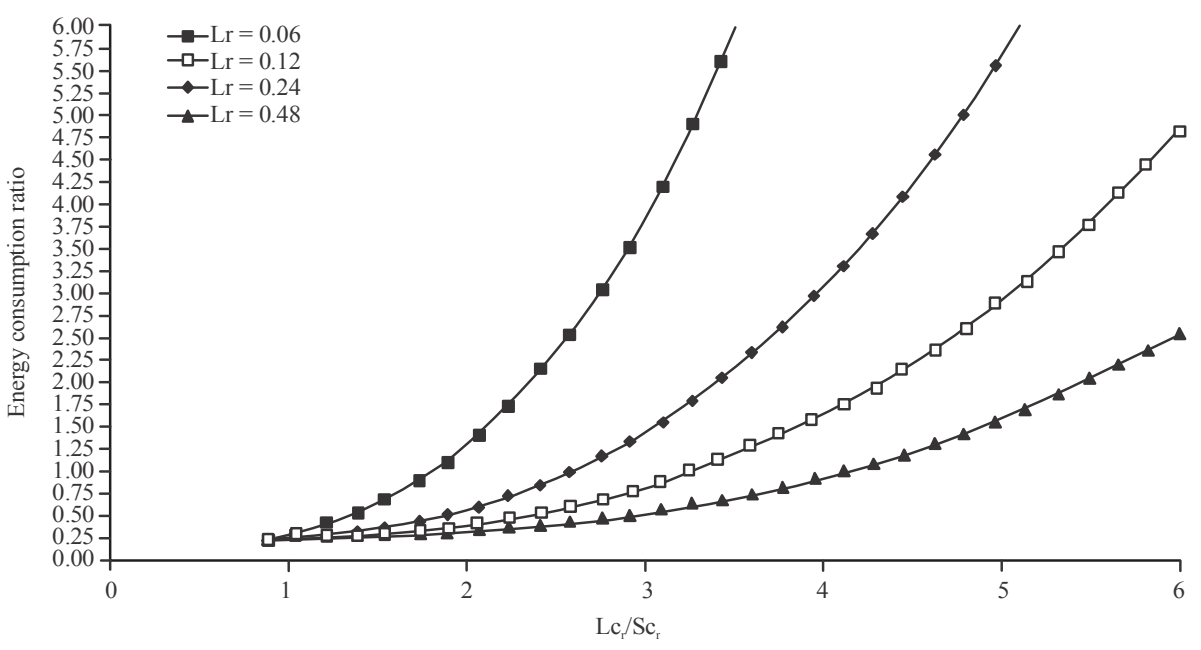

Fig. 4: Ratio of consumed energy by nodes at $\lambda=3, \mathrm{~S}_{\mathrm{r}}=8 \mathrm{~m}, \mathrm{Sc}_{\mathrm{r}}=7 \mathrm{~m}, \mathrm{Lc}_{\mathrm{r}}=7-50 \mathrm{~m}$

Table 3: The comparison of inhomogeneous results at $\mathrm{Lc}_{\mathrm{r}}=3-50 \mathrm{~m}, \mathrm{Sc}_{\mathrm{r}}=3 \mathrm{~m}$ with homogenous results

\begin{tabular}{|c|c|c|c|c|c|c|}
\hline \multirow{3}{*}{$\begin{array}{l}\text { No. of } \\
\text { deployed nodes }\end{array}$} & \multirow{3}{*}{$\begin{array}{l}\text { Homogeneous nodes } \\
\text { connection }(\%) \\
\text { when } \mathrm{S}_{\mathrm{r}}=8 \mathrm{~m}\end{array}$} & \multicolumn{5}{|l|}{ Ratio of LCR/LCR models } \\
\hline & & Ratio of $\mathrm{Lc}_{\mathrm{r}} / \mathrm{Sc}_{\mathrm{r}}(\mathrm{m})$ & $\mathrm{L}_{\mathrm{r}} 0.06(\%)$ & $\mathrm{L}_{\mathrm{r}} 0.12(\%)$ & $\mathrm{L}_{\mathrm{r}} 0.24(\%)$ & $\mathrm{L}_{\mathrm{r}} 0.48(\%)$ \\
\hline & & Inhomogeneous communication range & $\mathrm{Lc}_{\mathrm{r}} / \mathrm{Sc}_{\mathrm{r}}=17.5$ & $\mathrm{Lc}_{r} / \mathrm{Sc}_{\mathrm{r}}=13.9$ & $\mathrm{Lc}_{\mathrm{r}} / \mathrm{Sc}_{\mathrm{r}}=11.1$ & $\mathrm{Lc}_{\mathrm{r}} / \mathrm{Sc}_{\mathrm{r}}=7.4$ \\
\hline $\mathrm{N}_{\mathrm{d}}=80$ & 14.0 & $\mathrm{Lc}_{\mathrm{r}}=3-50, \mathrm{Sc}_{\mathrm{r}}=3$ & 5 & 7 & 11 & 35 \\
\hline $\mathrm{N}_{\mathrm{d}}=160$ & 44.0 & $\mathrm{Lc}_{\mathrm{r}}=3-50, \mathrm{Sc}_{\mathrm{r}}=3$ & 5 & 11 & 23 & 66 \\
\hline $\mathrm{N}_{\mathrm{d}}=240$ & 94.0 & $\mathrm{Lc}_{\mathrm{r}}=3-50, \mathrm{Sc}_{\mathrm{r}}=3$ & 7 & 14 & 26 & 67 \\
\hline $\mathrm{N}_{\mathrm{d}}=320$ & 98.0 & $\mathrm{Lc}_{\mathrm{r}}=3-50, \mathrm{Sc}_{\mathrm{r}}=3$ & 8 & 15 & 29 & 72 \\
\hline$\underline{N_{d}}=400$ & 99.9 & $\mathrm{Lc}_{\mathrm{r}}=3-50, \mathrm{Sc}_{\mathrm{r}}=3$ & 9 & 16 & 32 & 72 \\
\hline
\end{tabular}


shows better communication network and performance. Further more, there is an enormous difference between the statistics representing the connection among sensor nodes of the homogeneous and in homogeneous distribution cases with the range $\mathrm{Sc}_{\mathrm{r}}$ and $\mathrm{Lc}_{\mathrm{r}}$ initialized with $3 \mathrm{~m}$. The second try and $\left(\mathrm{Sc}_{\mathrm{r}}\right.$ and $\mathrm{Lc}_{\mathrm{r}}$ initialized with $7 \mathrm{~m}$ ) presents grater ratio of connectivity with a great amount of nodes.

It can be explained as follows; the first try results came by using low communication range. Furthermore,

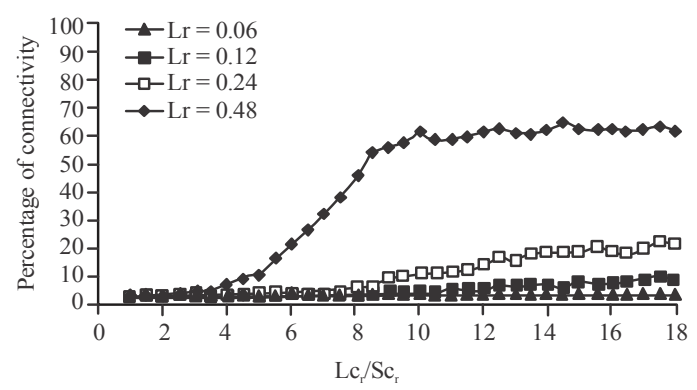

Fig. 5: Measurements of sensor nodes connectivity in the network at $\mathrm{N}_{\mathrm{d}}=80, \mathrm{Lc}_{\mathrm{r}}=3-50 \mathrm{~m}, \mathrm{Sc}_{\mathrm{r}}=3 \mathrm{~m}$ (calculations of connectivity average over 30 runs) with $3 \mathrm{~m}$ for $\mathrm{Sc}_{\mathrm{r}}$ and from 3-50 $\mathrm{m}$ for $\mathrm{Lc}_{\mathrm{r}}$. Hence, many sensors have been out of range due to small communication ranges in particular the sensors with $\mathrm{Sc}_{\mathrm{r}}$.

It seems that the sensors with $\mathrm{Sc}_{\mathrm{r}}$ look like undercritical range, therefore, full connected network could not be obtained. Both types of nodes must exceed a certain critical range for a connected network. These observations correspond to observations Bettstetter, (2002).

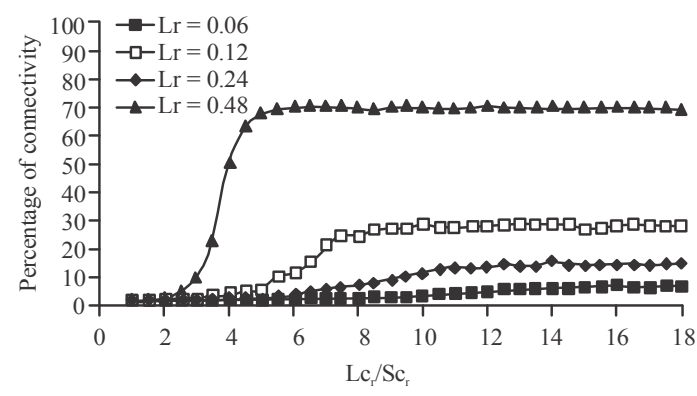

Fig. 6: Measurements of sensor nodes connectivity in the network at $\mathrm{N}_{\mathrm{d}}=400, \mathrm{Lc}_{\mathrm{r}}=3-50 \mathrm{~m}, \mathrm{Sc}_{\mathrm{r}}=3 \mathrm{~m}$ (calculations of connectivity average over 30 runs)

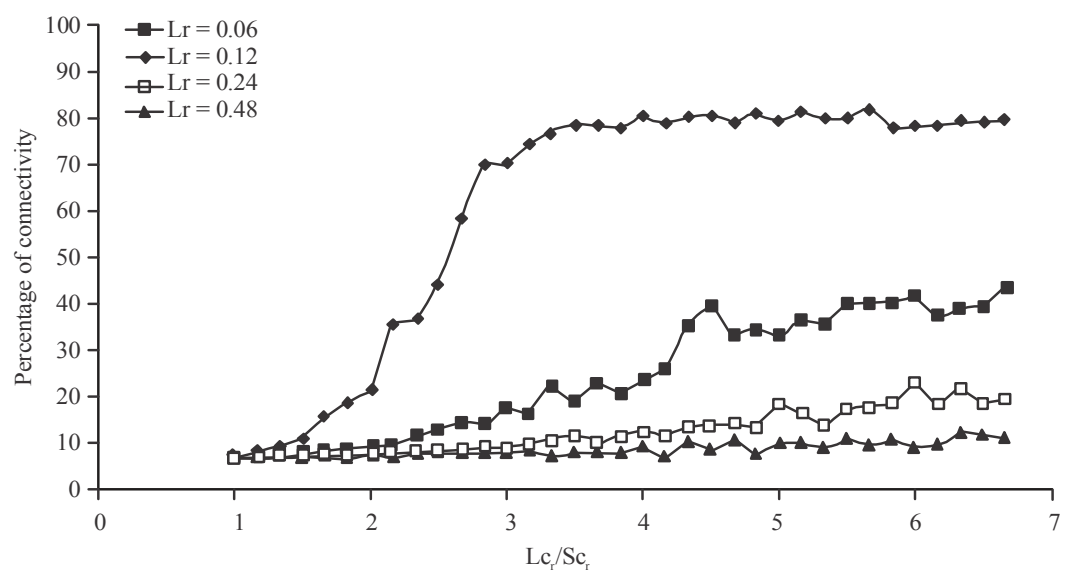

Fig. 7: Measurements of sensor nodes connectivity in the network at $\mathrm{N}_{\mathrm{d}}=80, \mathrm{Lc}_{\mathrm{r}}=7-50 \mathrm{~m}, \mathrm{Sc}_{\mathrm{r}}=7 \mathrm{~m}$ (calculations of connectivity average over 30 runs)

Table 4: The comparison of inhomogeneous results at $\mathrm{Lc}_{\mathrm{r}}=5-50 \mathrm{~m}$ and $\mathrm{Sc}_{\mathrm{r}}=8 \mathrm{~m}$ with homogenous results

\begin{tabular}{|c|c|c|c|c|c|c|}
\hline \multirow{3}{*}{$\begin{array}{l}\text { No. of } \\
\text { deployed nodes }\end{array}$} & \multirow{3}{*}{$\begin{array}{l}\text { Homogeneous nodes } \\
\text { connection }(\%) \\
\text { when } S_{r}=8 \mathrm{~m}\end{array}$} & \multicolumn{5}{|l|}{ Ratio of LCR/LCR models } \\
\hline & & Ratio of $\mathrm{Lc}_{\mathrm{r}} / \mathrm{Sc}_{\mathrm{r}}(\mathrm{m})$ & $\mathrm{L}_{\mathrm{r}} 0.06(\%)$ & $\mathrm{L}_{\mathrm{r}} 0.12(\%)$ & $\mathrm{L}_{\mathrm{r}} 0.24(\%)$ & $\mathrm{L}_{\mathrm{r}} 0.48(\%)$ \\
\hline & & Inhomogeneous communication range & $\mathrm{Lc}_{\mathrm{r}} / \mathrm{Sc}_{\mathrm{r}}=5.7$ & $\mathrm{Lc}_{\mathrm{r}} / \mathrm{Sc}_{\mathrm{r}}=4.4$ & $\mathrm{Lc}_{\mathrm{r}} / \mathrm{Sc}_{\mathrm{r}}=3.6$ & $\mathrm{Lc}_{\mathrm{r}} / \mathrm{Sc}_{\mathrm{r}}=2.5$ \\
\hline $\mathrm{N}_{\mathrm{d}}=80$ & 14.0 & $\mathrm{Lc}_{\mathrm{r}}=7-50, \mathrm{Sc}_{\mathrm{r}}=8$ & 10 & 14 & 21 & 45 \\
\hline $\mathrm{N}_{\mathrm{d}}=160$ & 44.0 & $\mathrm{Lc}_{\mathrm{r}}=7-50, \mathrm{Sc}_{\mathrm{r}}=8$ & 21 & 42 & 63 & 92 \\
\hline $\mathrm{N}_{\mathrm{d}}=240$ & 94.0 & $\mathrm{Lc}_{\mathrm{r}}=7-50, \mathrm{Sc}_{\mathrm{r}}=8$ & 58 & 71 & 86 & 95 \\
\hline $\mathrm{N}_{\mathrm{d}}=320$ & 98.0 & $\mathrm{Lc}_{\mathrm{r}}=7-50, \mathrm{Sc}_{\mathrm{r}}=8$ & 86 & 91 & 95 & 97 \\
\hline $\mathrm{N}_{\mathrm{d}}=400$ & 99.9 & $\mathrm{Lc}_{\mathrm{r}}=7-50, \mathrm{Sc}_{\mathrm{r}}=8$ & 96 & 97 & 98 & 99 \\
\hline
\end{tabular}




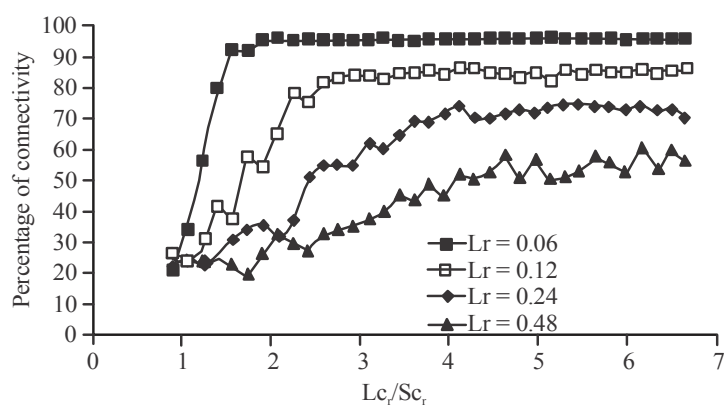

Fig. 8: Measurements of sensor nodes connectivity in the network at $\mathrm{N}_{\mathrm{d}}=240, \mathrm{Lc}_{\mathrm{r}}=7-50 \mathrm{~m}, \mathrm{Sc}_{\mathrm{r}}=8 \mathrm{~m}$ (calculations of connectivity average over 30 runs)

\section{CONCLUSION}

In this study, connectivity assessment is performed using inhomogeneous and homogeneous deployment strategy for ad-hoc sensors. Two strategies, homogeneous and inhomogeneous are evaluated to determine the higher connectivity. Consumption of power was considered in both. The simulations reveal that the network shows better connectivity when homogeneous sensor deployments are used rather than using inhomogeneous sensors network forming as a directed graph varied from previous analysis using undirected graphs. Phase transition has been shown in the network which used directed graphs in the simulation. At last, after manipulating manysimulations, it's clear that the networks with homogeneous sensors deployments offer greater communication capabilities between nodes for limited energy. The study confirmed previous works that investigated wireless ad hoc network communication properties. Future research may involve the development of the network's directed graph model for further investigation of network connectivity properties. In addition, a specific deployment strategy for ad-hoc networks also requires more complex energy consumption and power constraint models to be used in future works.

\section{NOTATIONS}

b : Sub-region of Ax

Ax : Finite region

$|A x|$ : Area of region Ax

$Z_{\beta}:$ 2D homogeneous Poisson point process

$\mathrm{L}_{\mathrm{s}}$ : Side-length of the region

$\mathrm{X}$ : The No. of sensors

$\varphi \quad:$ Nodes density

$\lambda \quad$ : Exponent factor of the path loss

$\mathrm{P}_{\mathrm{n}} \quad$ : The path between the two sensors

$\mathrm{P} \quad$ : Probability of having (LCR) sensors $\mathrm{s}_{\mathrm{i}}, \mathrm{S}_{\mathrm{j}}:$ Arbitrary sensor nodes

a : Random point

LCR : Large Communication Range sensor

SCR : Small Communication Range sensor

$Z \beta \quad$ : Location of sensors $s_{i}$ and $s_{j}$

\section{REFERENCES}

Akyildiz, I.F. and M.C. Vuran, 2010. Wireless Sensor Networks. Vol. 4, John Wiley \& Sons, Hoboken, New Jersey, USA., ISBN:9780470515198, Pages: 493.

Ammari, H.M. and S.K. Das, 2008. Integrated coverage and connectivity in wireless sensor networks: A two-dimensional percolation problem. IEEE. Trans. Comput., 57: 1423-1434.

Bettstetter, C., 2002. On the connectivity of wireless multihop networks with homogeneous and inhomogeneous range assignment. Proc. VTC 2002-Fall Vehicular Technol. Conf., 3: 1706-1710.

Chen, C., R.C. Elliott, W.A. Krzymien and J. Melzer, 2018. Modeling of cellular networks using stationary and nonstationary point processes. IEEE. Access, 6: 47144-47162.

Chiu, S.N., D. Stoyan, W.S. Kendall and J. Mecke, 2013. Stochastic Geometry and its Applications. 3rd Edn., John Wiley \& Sons, Hoboken, New Jersey, USA., ISBN:978-0-470-66481-0, Pages: 582.

Diestel, R., 2016. Graph Theory. 5th Edn., Springer, Berlin, Germany, ISBN:9783662575604, Pages: 428.

Dousse, O., P. Thiran and M. Hasler, 2002. Connectivity in ad-hoc and hybrid networks. Proceedings of the 21 st Annual Joint Conference of the IEEE Computer and Communications Societies, Volume 2, June 23-27, 2002, New York, USA., pp: 1079-1088.

Dung, L.T. and B. An, 2015. A simulation approach for analysis of multi-hop connectivity in cognitive radio ad-hoc networks. Proceedings of the 2015 International Conference on Information Networking (ICOIN), January 12-14, 2015, IEEE, Cambodia, Cambodia, pp: 386-387.

Khanjary, M., M. Sabaei and M.R. Meybodi, 2014. Critical density for coverage and connectivity in two-dimensional aligned-orientation directional sensor networks using continuum percolation. IEEE. Sens. J., 14: 2856-2863.

Kong, Z. and E.M. Yeh, 2007. Distributed energy management algorithm for large-scale wireless sensor networks. Proceedings of the 8th ACM International Symposium on Mobile Ad Hoc Networking and Computing, September 09-14, 2007, ACM, Montreal, Quebec, Canada, ISBN:978-1-59593-684-4, pp: 209-218. 
Lu, D., X. Huang, P. Li and J. Fan, 2012. Connectivity of large-scale cognitive radio ad hoc networks. Proceedings of the IEEE International Conference on Infocom, March 25-30, 2012, IEEE, Orlando, Florida, USA., ISBN:978-1-4673-0773-4, pp: 1260-1268.

Miorandi, D. and E. Altman, 2005. Coverage and connectivity of ad hoc networks presence of channel randomness. Proceedings IEEE 24th

Annual Joint International Conference on Computer and Communications Societies Vol. 1, March 13-17, 2005, IEEE, Miami, Florida, USA., pp: 491-502.
Philips, T.K., S.S. Panwar and A.N. Tantawi, 1989. Connectivity properties of a packet radio network model. IEEE Trans. Inform. Theory, 35: 1044-1047.

Xing, F. and W. Wang, 2008. On the critical phase transition time of wireless multi-hop networks with random failures. Proceedings of the 14th ACM International Conference on Mobile Computing and Networking, September 14-19, 2008, ACM, San Francisco, California, USA., ISBN:978-1-60558-096-8, pp: 175-186.

Xing, G., X. Wang, Y. Zhang, C. Lu, R. Pless and C. Gill, 2005. Integrated coverage and connectivity configuration for energy conservation in sensor networks. ACM Trans. Sensor Networks, 1: 36-72. 